\title{
Gestational weight gain across continents and ethnicity: systematic review and meta-analysis of maternal and infant outcomes in more than one million women
}

Rebecca F. Goldstein ${ }^{1,2}$, Sally K. Abell ${ }^{1,2}$, Sanjeeva Ranasinha ${ }^{1}$, Marie L. Misso ${ }^{1}$, Jacqueline A. Boyle ${ }^{1}$, Cheryce L. Harrison', Mary Helen Black', Nan Li', Gang Hu ${ }^{5}$, Francesco Corrado ${ }^{6}$, Hanne Hegaard ${ }^{7}$, Young Ju Kim ${ }^{8}$, Margaretha Haugen ${ }^{9}$, Won O. Song ${ }^{10}$, Min Hyoung Kim ${ }^{11}$, Annick Bogaerts ${ }^{12,13,14}$, Roland Devlieger ${ }^{15,16}$, Judith H. Chung ${ }^{17}$ and Helena J. Teede $\mathrm{e}^{1,2^{*}}$

\begin{abstract}
Background: The association between Institute of Medicine (IOM) guidelines and pregnancy outcomes across ethnicities is uncertain. We evaluated the associations of gestational weight gain (GWG) outside 2009 IOM guidelines, with maternal and infant outcomes across the USA, western Europe and east Asia, with subgroup analyses in Asia. The aim was to explore ethnic differences in maternal prepregnancy body mass index (BMI), GWG and health outcomes across these regions.

Methods: Systematic review, meta-analysis and meta-regression of observational studies were used for the study. MEDLINE, MEDLINE In-Process, Embase and all Evidence-Based Medicine (EBM) Reviews were searched from 1999 to 2017. Studies were stratified by prepregnancy BMI category and total pregnancy GWG. Odds ratio (ORs) 95\% confidence intervals (CI) applied recommended GWG within each BMI category as the reference. Primary outcomes were small for gestational age (SGA), preterm birth and large for gestational age (LGA). Secondary outcomes were macrosomia, caesarean section and gestational diabetes.
\end{abstract}

Results: Overall, 5874 studies were identified and 23 were included $(n=1,309,136)$. Prepregnancy overweight/ obesity in the USA, Europe and Asia was measured at 42\%,30\% and 10\% respectively, with underweight 5\%, 3\% and 17\%. GWG below guidelines in the USA, Europe and Asia was 21\%, 18\% and 31\%, and above was 51\%, 51\% and 37\% respectively. Applying regional BMI categories in Asia showed GWG above guidelines (51\%) was similar to that in the USA and Europe.

GWG below guidelines was associated with a higher risk of SGA (USA/Europe [OR 1.51; Cl 1.39, 1.63]; Asia [1.63; 1.45, 1.82]) and preterm birth (USA/Europe [1.35; 1.17, 1.56]; Asia [1.06; 0.78, 1.44]) than GWG within guidelines. GWG above guidelines was associated with a higher risk of LGA (USA/Europe [1.93; 1.81, 2.06]; Asia [1.68; 1.51, 1.87]), macrosomia (USA/Europe $[1.87 ; 1.70,2.06]$; Asia $[2.18 ; 1.91,2.49])$ and caesarean (USA/Europe [1.26; 1.21, 1.33]; Asia [1.37; 1.30, 1.45]). Risks remained elevated when regional BMI categories were applied for GWG recommendations. More women in Asia were categorised (Continued on next page)

\footnotetext{
* Correspondence: helena.teede@monash.edu

${ }^{1}$ Monash Centre for Health Research and Implementation, Monash University,

Clayton, VIC, Australia

${ }^{2}$ Monash Diabetes and Endocrine Units, Monash Health, Locked Bag 29,

Clayton Rd, Clayton, VIC 3168, Australia

Full list of author information is available at the end of the article
}

(c) The Author(s). 2018 Open Access This article is distributed under the terms of the Creative Commons Attribution 4.0 International License (http://creativecommons.org/licenses/by/4.0/), which permits unrestricted use, distribution, and reproduction in any medium, provided you give appropriate credit to the original author(s) and the source, provide a link to the Creative Commons license, and indicate if changes were made. The Creative Commons Public Domain Dedication waiver (http://creativecommons.org/publicdomain/zero/1.0/) applies to the data made available in this article, unless otherwise stated. 
(Continued from previous page)

as having GWG below guidelines using World Health Organization (WHO) (60\%) compared to regional BMI categories (16\%), yet WHO BMI was not accompanied by increased risks of adverse outcomes.

Conclusions: Women in the USA and western Europe have higher prepregnancy BMI and higher rates of GWG above guidelines than women in east Asia. However, when using regional BMI categories in east Asia, rates of GWG above guidelines are similar across the three continents. GWG outside guidelines is associated with adverse outcomes across all regions. If regional BMI categories are used in east Asia, IOM guidelines are applicable in the USA, western Europe and east Asia.

Keywords: Pregnancy, Ggestational weight gain, Maternal and infant outcomes, Obesity, Small for gestational age, Large for gestational age, Gestational diabetes, Caesarean section, Macrosomia, Preterm birth

\section{Background}

Gestational weight gain (GWG) is influenced by many factors including the obesogenic environment, prepregnancy body mass index (BMI), age, parity, smoking, socioeconomic status and comorbid medical conditions $[1,2]$. Excess or insufficient GWG is associated with higher risks of adverse pregnancy outcomes, including preterm birth, macrosomia and caesarean delivery [3]. The US Institute of Medicine (IOM) developed GWG guidelines in 1990 and updated them in 2009 (Table 1), yet nearly three quarters of women now gain weight outside these guidelines [4, 5]. Given that lifestyle intervention improves outcomes, meeting GWG guidelines is an important target [6]. However, the IOM guidelines are based on data from primarily USA-dwelling, Caucasian and Black women, with limited ethnic diversity that may not be applicable to women from Europe and Asia. Given that Asia is the most populous continent, inhabited by $60 \%$ of the world's population, applicability of GWG guidelines to Asian populations is an international public health priority.

At lower BMI, people from Asia have a greater risk for cardiovascular disease and diabetes $[7,8]$ than Caucasians, with a higher body fat percentage and greater central obesity [9]. During pregnancy, women from Asian countries have different risk profiles than Caucasian women. Asian-American women have a higher risk of gestational diabetes mellitus (GDM), caesarean section and low birthweight babies, and a lower risk of gestational hypertension and macrosomia compared to non-Hispanic white women [10]. Amongst Asian women, Korean and Taiwanese women have greater GWG and postpartum weight retention than women from other Asian countries [11]. In this context, GWG guidelines in Asian women may need to be considered differently; however, there is insufficient comparative research to date.

The 2009 IOM guidelines, although based on limited data, showed no ethnic differences in associations between GWG and pregnancy outcomes, whilst calling for further research [4]. Currently, there are no specific GWG guidelines for women from Asia. Most Asian studies use Caucasian-derived IOM GWG guidelines, and some use their own regional guidelines [12]. This creates heterogeneity and limits comparisons across regions, underpinning calls for new ethnic-specific regional GWG guidelines in China [13], highlighting gaps in current guidelines.

In this systematic review, meta-analysis and meta-regression, we aimed to explore ethnic differences in maternal prepregnancy BMI, GWG and health outcomes across the USA, Europe and Asia. In Asia, we also aimed to explore GWG and health outcomes using ethnic-specific regional BMI and World Health Organization (WHO) BMI categories.

\section{Methods}

This systematic review and meta-analysis was conducted according to the Preferred Reporting Items for Systematic Reviews and Meta-Analyses (PRISMA) protocol. This protocol was registered with the PROSPERO International Prospective Register of Systematic reviews (registration number CRD42015023325). An analysis of all pooled data is published [5]. This study focused on ethnic differences in maternal BMI, GWG and maternal and neonatal outcomes.

The methods used for study eligibility, data extraction and risk of bias have been detailed previously [5] (search

Table 12009 IOM Recommendations for gestational weight gain during pregnancy

\begin{tabular}{lllll}
\hline Recommendations & Underweight & Normal weight & Overweight & Obese \\
\hline Prepregnancy BMI $\left(\mathrm{kg} / \mathrm{m}^{2}\right)$ & $<18.5$ & $18.5-24.9$ & $25.0-29.9$ & $\mathbf{2}$ \\
Total weight gain range $(\mathrm{kg})$ & $12.5-18$ & $11.5-16$ & $7-11.5$ & $5-9$ \\
Total weight gain range (lbs) & $28-40$ & $25-35$ & $15-24$ & $11-20$ \\
\hline
\end{tabular}

Adapted from 2009 IOM guidelines 
terms and search strategy are discussed in Additional files 1 and 2). Briefly, observational studies published in the English language between January 1999 and February 2017, with a sample size of more than 500 women were included. Studies assessing multiple pregnancies and pregnancies in women $<18$ years were excluded. Inclusion required that studies present data examining the women by prepregnancy BMI category (underweight, normal weight, overweight, obese), stratified by the total pregnancy GWG (studies using weekly GWG were excluded). The odds ratio (OR) for each outcome had to be stratified by maternal BMI and GWG. Papers that mutually adjusted for BMI and GWG were excluded.

After identifying wide variations in prepregnancy BMI and GWG categories, meaningful interpretation and meta-analysis were not possible. Relevant authors were contacted to reanalyse and present data using consistent categories. Chinese and Korean studies used ethnic-specific BMI categories (China: underweight BMI $<18.5 \mathrm{~kg} / \mathrm{m}^{2}$, normal weight $18.5-23.9 \mathrm{~kg} / \mathrm{m}^{2}$, overweight 24-28 kg/m ${ }^{2}$ and obese $\geq 28 \mathrm{~kg} / \mathrm{m}^{2}$; Korea: underweight BMI $<18.5 \mathrm{~kg} / \mathrm{m}^{2}$, normal weight $18.5-22.9 \mathrm{~kg} / \mathrm{m}^{2}$, overweight $23-25 \mathrm{~kg} / \mathrm{m}^{2}$ and obese $\geq 25 \mathrm{~kg} / \mathrm{m}^{2}$ ) whilst Japanese and Taiwanese studies used WHO BMI categories (underweight $<18.5 \mathrm{~kg} / \mathrm{m}^{2}$, normal weight $18.5-24.9 \mathrm{~kg} / \mathrm{m}^{2}$, overweight $25-$ $29.9 \mathrm{~kg} / \mathrm{m}^{2}$ and obese $\geq 30 \mathrm{~kg} / \mathrm{m}^{2}$ ).

Primary outcomes were (1) small for gestational age (SGA): < 10th percentile of birthweight for sex and gestational age, (2) pre-term birth: spontaneous birth $<37$ weeks gestation, (3) large for gestational age (LGA): > 90th percentile of birthweight for sex and gestational age. Secondary outcomes were (1) macrosomia: birthweight $>4000 \mathrm{~g}$, (2) caesarean section and (3) GDM.

\section{Strategy for data synthesis}

Study findings were synthesised based on target population characteristics, type of study and outcome. Proportions were calculated using the pooled number in a group divided by the total number (\%). The chi-squared test was used to assess difference in proportion of women within BMI categories and GWG categories between regions. The two-sample test of proportions was used to assess differences between two particular regions.

Summaries of outcomes associated with GWG were produced for each study by calculating the ORs and $95 \%$ confidence intervals (CIs), using the recommended GWG within each BMI category as the reference. Where two or more studies assessed the same outcome, the results were pooled using random-effects meta-analysis, calculating the OR and 95\% CI for each outcome. Extracted pooled ORs for each outcome were combined to construct a summary pooled OR for all outcomes. Crude data was used where possible given the variation in control for confounding factors. However, some papers presented adjusted ORs only [14-21]. US and European studies were combined as one group in the meta-analysis of pregnancy outcomes (to allow for two or more studies to assess each outcome) and compared to Asian studies. We were unable to demonstrate statistical significance for comparison of ORs for SGA, preterm birth, LGA, macrosomia and caesarean section between the US/Europe and Asian studies due to similar ORs and overlap in CIs.

Heterogeneity was assessed using the $I^{2}$ statistic. An $I^{2}$ value greater than $50 \%$ was indicative of substantial heterogeneity [22]. Where there was sufficient data available, a meta-regression analysis was performed to investigate sources of heterogeneity, including percentage of smokers in pregnancy, mean age and percentage nulliparity. Sufficient data on race/ethnicity was not available for inclusion in the meta-regression. Studies from Europe and Asia did not provide information regarding race or ethnicity. Studies from the USA provided race/ethnicity data; however, this varied with reporting methods (some report percentage of total population, others report percentage stratified by GWG).

A further analysis of women living in Asian countries was performed comparing studies using regional BMI categories (Chinese and Korean studies) and WHO BMI categories (Japanese and Taiwanese) assessing alignment with 2009 IOM GWG guidelines and maternal and infant adverse outcomes. Statistical analysis used Stata software v.14 and was supported by a biostatistician (SR).

\section{Results}

From 5874 studies identified by the initial search, 302 studies were selected for full text review (Fig. 1) and 261 studies were excluded, using a priori selection criteria. Forty papers grouped women by prepregnancy BMI category (underweight, normal weight, overweight, obese), stratified by the total GWG for the pregnancy. One study [23] did not initially meet inclusion criteria because ORs were not stratified by both BMI and GWG. However, through collaborations, this data was available in the required format. Where required, authors were contacted for data reanalysis, and 13 collaborated (Additional file 2).

In total, 23 cohort studies [12, 14-21, 23-36] were included in this systematic review and meta-analysis, reporting data on more than 1 million women $(n=1,309,136)$.

\section{Study characteristics}

Table 2 describes the study design and size, eligibility criteria and outcomes (descriptive characteristics are shown in Additional file 3: Table S1). Eighteen studies were retrospective, five were prospective $[14,25,28,31,36]$. Ten studies were from the USA [14, 17, 18, 20, 23, 27, 29, 30, 


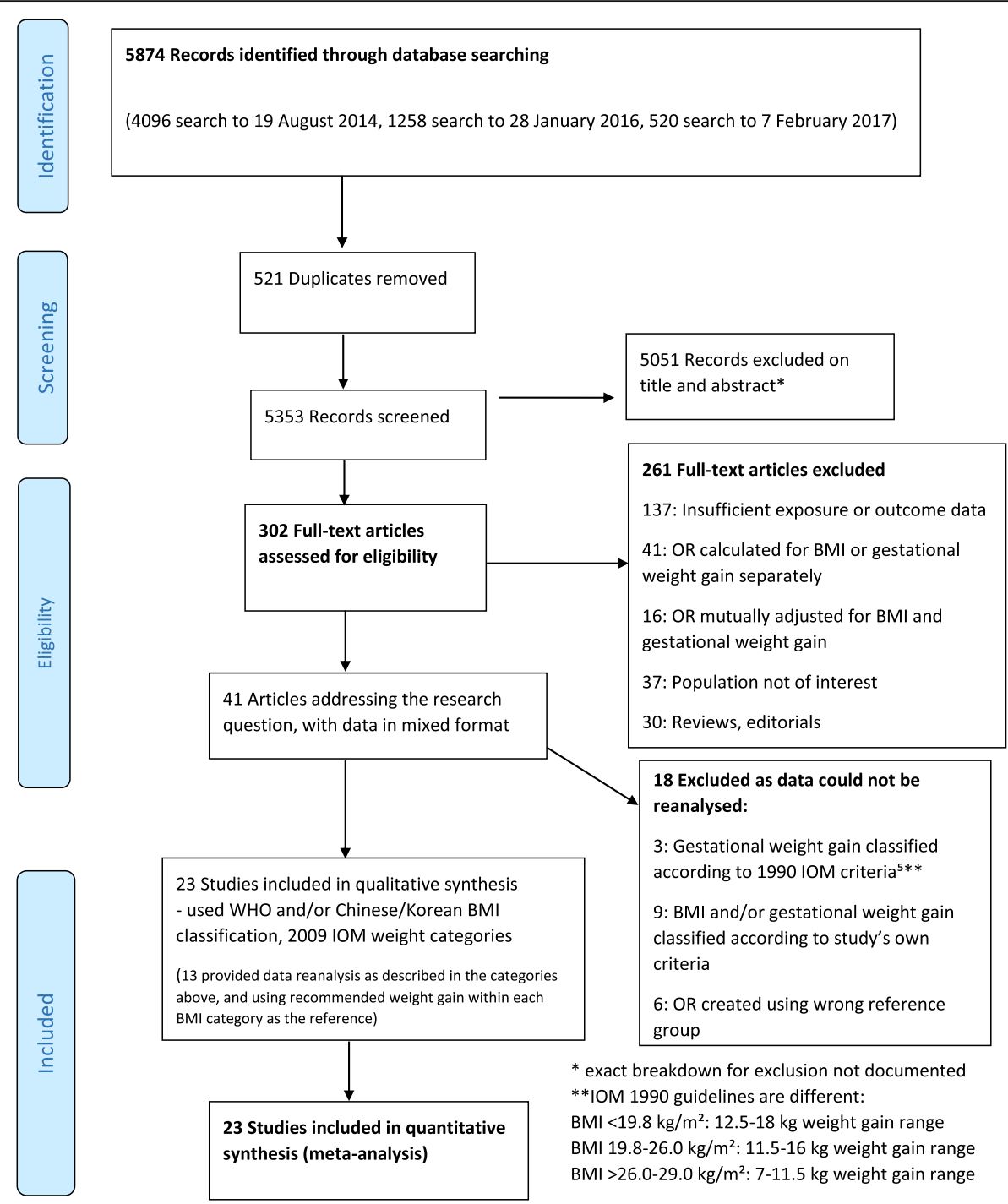

Fig. 1 Flow Diagram of study selection process

32, 33], five from western Europe (one each from Norway [25], Belgium [35], Italy [24], Denmark [28] and Sweden [15]) and eight from east Asia (four from China [16, 26, $31,36]$, two from Korea [12, 34], one each from Taiwan [21] and Japan [19]). The sample size ranged from 1034 to 570,672 .

Overall, 66\% $(n=865,790)$ of women were from the USA, $10 \%(n=125,203)$ from Western Europe and $24 \%$ $(n=318,143)$ from east Asia.

\section{Analysis by region: USA, Europe and Asia}

In the descriptive analysis of maternal BMI only, it was required to exclude two European studies $[15,35](52 \%$ of European women) and four US studies [18, 20, 30, 32] (3\% of US women) which studied obese women only, and one Asian study [16] (4\% of Asian women) which studied normal weight women only. In the remaining studies, overweight and obesity were present in $43 \%$ of women in the USA, $31 \%$ in Europe and 10\% in Asia (Table 3). Underweight BMI was present in 5\% in the USA, 3\% in Europe and 17\% in Asia. The proportion of women within each BMI category was different between the regions $(p<0.0001)$ (using the chi-squared test).

Overall, underweight women had the greatest prevalence of GWG below guidelines (43\%), whereas overweight women, followed by obese women, had the greatest prevalence of GWG above guidelines (64\% and $60 \%$ respectively) (Table 4 ).

For GWG below guidelines, prevalence was $21 \%, 18 \%$ and $31 \%$ in the USA, Europe and Asia respectively, including all Asian data (Table 5). The proportion of women gaining below guidelines was different between the three regions $(p<0.0001)$ (using the chi-squared test). 
Table 2 Characteristics of 23 included studies

\begin{tabular}{|c|c|c|c|c|c|c|}
\hline Study & Country & Study period & Study design & Sample size & Setting & Outcomes \\
\hline $\begin{array}{l}\text { Durst, } \\
2016[20]\end{array}$ & USA & $2000-2014$ & Retrospective & 5651 & $\begin{array}{l}\text { University of Alabama, } \\
\text { Birmingham }\end{array}$ & $\begin{array}{l}\text { SGA, LGA, macrosomia, } \\
\text { caesarean section }\end{array}$ \\
\hline $\begin{array}{l}\text { Enomoto, } \\
2016[19]\end{array}$ & Japan & 2013 & Retrospective & 97,157 & $\begin{array}{l}\text { Japan Society of Obstetrics and } \\
\text { Gynaecology Registry system } \\
\text { with } 280 \text { participating hospitals }\end{array}$ & $\begin{array}{l}\text { SGA, preterm birth, LGA, } \\
\text { macrosomia, caesarean }\end{array}$ \\
\hline $\begin{array}{l}\text { Hung, } \\
2016[21]\end{array}$ & Taiwan & 2009-2015 & Retrospective & 10,973 & $\begin{array}{l}\text { Taipei Chang Gung } \\
\text { Memorial Hospital }\end{array}$ & SGA, LGA, macrosomia, caesarean section \\
\hline $\begin{array}{l}\text { Xiong }^{e} \\
2016[36]\end{array}$ & China & 2012-2013 & Prospective & 57,891 & Hospitals and community centres & Caesarean section \\
\hline $\begin{array}{l}\text { Bogaerts, } \\
2015[35]\end{array}$ & Belgium & 2009-2011 & Retrospective & 18,053 & Flemish study center for perinatal & Caesarean section, macrosomia, LGA \\
\hline $\begin{array}{l}\text { Shin, } \\
2015 \text { [33] }\end{array}$ & USA & 2004-2011 & Retrospective & 219,868 & $\begin{array}{l}\text { Pregnancy risk assessment } \\
\text { monitoring system (PRAMS) }\end{array}$ & Preterm birth, SGA, LGA \\
\hline $\begin{array}{l}\text { Wen }^{\mathrm{e}} \\
2015 \text { [16] }\end{array}$ & China & 2009-2013 & Retrospective & 13,776 & Jishuitan Hospital & Preterm birth \\
\hline $\begin{array}{l}\text { Yange, } \\
2015 \text { [31] }\end{array}$ & China & $2011-2013$ & Prospective & 85,765 & $\begin{array}{l}\text { Wuhan Women and Children } \\
\text { Health Care Center }\end{array}$ & Macrosomia \\
\hline $\begin{array}{l}\text { Badon, } \\
2014[14]\end{array}$ & USA & 2000-2006 & Prospective & 5297 & $\begin{array}{l}\text { North American Field Centers, } \\
\text { HAPO }\end{array}$ & LGA \\
\hline $\begin{array}{l}\text { Chihara, } \\
2014[17]\end{array}$ & USA & $2003-2005$ & Retrospective & 19,130 & $\begin{array}{l}\text { Hawaii's special supplemental } \\
\text { program for women, infants } \\
\text { and children (WIC) }\end{array}$ & Macrosomia \\
\hline $\begin{array}{l}\text { Haugenc, } \\
2014[25]\end{array}$ & Norway & 1999-2008 & Prospective & 56,082 & $\begin{array}{l}\text { Norwegian Mother and } \\
\text { Child cohort study }\end{array}$ & Macrosomia, caesarean section \\
\hline $\begin{array}{l}\text { Lee }^{\mathrm{d}}, \\
2014 \text { [34] }\end{array}$ & Korea & 2010-2012 & Retrospective & 16,297 & Single medical centre & LGA \\
\hline $\begin{array}{l}\text { Swank, } \\
2014[32]\end{array}$ & USA & 2007 & Retrospective & 1034 & Californian birth certificate data & Caesarean, macrosomia \\
\hline $\begin{array}{l}\text { Black, } \\
2013 \text { [23] }\end{array}$ & USA & $2005-2010$ & Retrospective & 9835 & $\begin{array}{l}\text { Kaiser Permanente } \\
\text { Southern California }\end{array}$ & $\begin{array}{l}\text { LGA (provided additional outcomes } \\
\text { in reanalysis incl. SGA, preterm, } \\
\text { macrosomia and caesarean section }\end{array}$ \\
\hline $\begin{array}{l}\text { Kominiarek }^{\mathrm{b}} \\
2013[18]\end{array}$ & USA & $2002-2008$ & Retrospective & 21,020 & 12 institutions (19 hospitals) & $\begin{array}{l}\text { Caesarean section, SGA, } \\
\text { LGA, macrosomia }\end{array}$ \\
\hline $\mathrm{Li}^{\mathrm{a}}, 2013[26]$ & China & 2009-2011 & Retrospective & 33,973 & $\begin{array}{l}\text { Tianjin Women's and } \\
\text { Children's Health Centre }\end{array}$ & $\begin{array}{l}\text { Caesarean, preterm delivery, LGA, } \\
\text { SGA macrosomia }\end{array}$ \\
\hline $\begin{array}{l}\text { Di Benedetto, } \\
2012[24]\end{array}$ & Italy & 2004-2009 & Retrospective & 2225 & University Hospital & Macrosomia, caesarean section \\
\hline $\begin{array}{l}\text { Moore Simas, } \\
2012[29]\end{array}$ & USA & $2006-2010$ & Retrospective & 11,203 & University Hospital & SGA, LGA \\
\hline $\begin{array}{l}\text { Blomberg, } \\
2011[15]\end{array}$ & Sweden & 1993-2008 & Retrospective & 46,595 & Swedish Medical birth registry & Caesarean, LGA, SGA \\
\hline $\begin{array}{l}\text { J Park } \\
2011 \text { [12] }\end{array}$ & Korea & 2005-2007 & Retrospective & 2311 & University Hospital & $\begin{array}{l}\text { SGA, LGA, macrosomia, } \\
\text { caesarean section, preterm birth }\end{array}$ \\
\hline $\begin{array}{l}\text { S Park, } \\
2011[27]\end{array}$ & USA & $2004-2007$ & Retrospective & 570,672 & Florida birth certificate data & SGA, LGA \\
\hline $\begin{array}{l}\text { Vesco, } \\
2011[30]\end{array}$ & USA & $2000-2005$ & Retrospective & 2080 & Kaiser Permanente group practice & Macrosomia, LGA, SGA \\
\hline Rode, 2007 [28] & Denmark & 1996-1998 & Prospective & 2248 & University Hospital & Macrosomia \\
\hline
\end{tabular}

${ }^{a}$ Data according to both Chinese and WHO BMI categories (Chinese used here)

bSample size changed when provided additional data, OR not recalculated

'Sample size changed when provided additional data

${ }^{\mathrm{d}}$ Data according to both Korean and WHO BMI categories (Korean used here)

e Data according to Chinese BMI categories

HAPO Hyperglycaemia and Adverse Pregnancy Outcomes, NR not reported 
Table 3 Body mass index prepregnancy by regions (\%)

\begin{tabular}{|c|c|c|c|c|}
\hline Region & Underweight & Normal weight & Overweight & Obese \\
\hline \multicolumn{5}{|l|}{ Including all studies } \\
\hline USA & 5 & 51 & 23 & 21 \\
\hline Europe & 1 & 33 & 10 & 6 \\
\hline Asia & 16 & 74 & 8 & 2 \\
\hline \multicolumn{5}{|c|}{ Excluding studies that assessed obese women $[15,18,20,30,32,35]$ or normal weight women only $[16]$} \\
\hline USA & 5 & 53 & 24 & 18 \\
\hline Europe & 3 & 67 & 21 & 9 \\
\hline Asia (overall) & 17 & 73 & 8 & 2 \\
\hline Asia (regional BMI) & 16 & 73 & 9 & 2 \\
\hline Asia (WHO BMI) & 18 & 71 & 8 & 3 \\
\hline
\end{tabular}

For GWG above guidelines, prevalence was 51\%, 51\% and $37 \%$ in the USA, Europe and Asia respectively, including all Asian data. The proportion of women above guidelines was different between the three regions $(p<$ 0.0001 ) (using the chi-squared test). GWG above guidelines was higher in the USA than Asia $(p<0.0001)$ and higher in Europe than Asia $(p<0.0001)$, but this was not true between the USA and Europe $(p=1.0)$ (using the two-sample test of proportions).

However, when Asian studies applying regional BMI categories only were analysed, GWG above guidelines (51\%) was no longer significantly different from GWG above guidelines in the USA and Europe $(p=0.28)$. There was a substantial difference between GWG below guidelines in Asia, using regional BMI (16\%), compared to WHO BMI categories when applying IOM guidelines (60\%).

A summary of pooled ORs for primary and secondary outcomes is given in Fig. 2a and b and Table 6. Pooled ORs for individual analyses for outcomes are presented in Additional file 4.

\section{Primary outcomes}

SGA: eleven studies (seven USA/Europe; four Asia) Eleven studies assessed SGA. This was defined as birthweight $<10$ th percentile for gestational age in five studies [12, 19, 26, 27, 33]; four additionally accounted for sex [21, 23, 25, 29], one for sex and race/ethnicity [30] and another for sex, race and parity [20].

Table 4 Proportions of women gaining below, within and above guidelines, stratified by prepregnancy BMI (\%)

\begin{tabular}{llll}
\hline BMl group & Below IOM & Within IOM & Above IOM \\
\hline Underweight & 43 & 36 & 21 \\
Normal weight & 28 & 36 & 36 \\
Overweight & 13 & 23 & 64 \\
Obese & 19 & 21 & 60 \\
\hline
\end{tabular}

Data from 20/23 studies: $n=1,146,350$ (88\% of total population). Excluding studies that did not stratify GWG by BMI category $[17,31,36]$
GWG below guidelines was associated with a higher risk for SGA than GWG within guidelines; for USA/Europe OR 1.51 (1.39-1.63), $I^{2}=88 \%$ and for Asia OR 1.63 $(1.45-1.82), I^{2}=63$. The association of SGA risk was highest with underweight women for both USA/Europe (1.95; 1.83-2.07) and Asia (1.90; 1.34-2.70).

GWG above guidelines was associated with lower risk for SGA than GWG within guidelines: USA/Europe (OR 0.65; $0.62-0.69) I^{2}=65 \%$ and Asia (OR 0.69; 0.63-0.76) $I^{2}=20 \%$.

\section{Preterm birth: five studies (two USA/Europe; three} Asia) Five studies assessed preterm birth ( $<37$ weeks gestation); four did not specify whether this was spontaneous or induced [16, 23, 26, 33] and one specified spontaneous and induced combined [19].

GWG below guidelines was associated with a higher risk for preterm birth than GWG within guidelines: USA/Europe (OR 1.35; 1.17-1.56) $I^{2}=81 \%$ and Asia (OR 1.06; 0.78-1.44) $I^{2}=86 \%$.

GWG above guidelines was associated with a lower risk for preterm birth than GWG within guidelines: USA/Europe (0.83; 0.74-0.94) $I^{2}=79 \%$ and Asia (OR $0.71 ; 0.58-0.87) I^{2}=68 \%$.

\section{LGA: thirteen studies (eight USA/Europe; five Asia)} Thirteen studies assessed LGA. This was defined as birthweight $>90$ th percentile for gestational age in six studies [12, 19, 26, 27, 33, 34]. Four defined LGA by additionally accounting for infant sex [21, 23, 25, 29], one for sex and race/ethnicity [30], one for sex, race and parity [20] and one for sex, parity and study centre [14].

GWG below guidelines was associated with a lower risk for LGA than GWG within guidelines: USA/Europe (OR 0.62; 0.57-0.68) $I^{2}=72 \%$ and Asia (OR 0.55; 0.48$0.63) I^{2}=78 \%$. The risk was lowest in the underweight women: (USA/Europe [OR 0.42; 0.30-0.60] and Asia [OR 0.42; 0.30-0.59]).

GWG above guidelines was associated with a higher risk for LGA: USA/Europe (OR 1.93; 1.81-2.06) $I^{2}=$ 
Table 5 Gestational weight gain during pregnancy by regions (\%)

\begin{tabular}{llll}
\hline Region & Below guidelines & Within guidelines & Above guidelines \\
\hline Including all studies & & & 28 \\
USA & 21 & 31 & 51 \\
Europe & 18 & 32 & 37 \\
Asia (overall) & 31 & 33 & 51 \\
Asia (regional BMI) & 16 & 31 & 9 \\
Asia (WHO BMI) & 60 &
\end{tabular}

Including all studies

$80 \%$ and Asia (OR 1.68; 1.51-1.87) $I^{2}=69 \%$. For both groups, the risk was greatest in underweight women, with risk decreasing as BMI increased.

\section{Secondary outcomes}

Macrosomia: twelve studies (seven USA/Europe; five Asia) Macrosomia was defined as birthweight $>4000 \mathrm{~g}$ in the majority $[12,17,19-21,23-26,28,31]$; one study used birthweight $>4500 \mathrm{~g}$ [30].

GWG below guidelines was associated with a lower risk for macrosomia than GWG within guidelines: USA/ Europe (OR 0.62; 0.54-0.70) $I^{2}=39 \%$ and Asia (OR $0.60 ; 0.47-0.77) I^{2}=79 \%$.

GWG above guidelines was associated with a higher risk for macrosomia: USA/Europe (OR 1.87; 1.70-2.06) $I^{2}=56 \%$ and Asia (OR 2.18; $\left.1.91-2.49\right) I^{2}=66 \%$. In Asia, the risk decreased as the BMI increased.

Caesarean section: nine studies (four USA/Europe; five Asia) Nine studies assessed caesarean section. Seven included emergency and elective deliveries [12, 19, 23-26, 36] and two did not specify [20, 21]. Two [20, 23] included repeat caesarean (total caesarean section), one primary caesarean only [21] and six did not distinguish these.

GWG below guidelines was associated with a lower risk for caesarean: USA/Europe (OR 0.92; 0.87-0.98) $I^{2}=0 \%$, with no statistically significant result for Asia (OR 0.98; 0.89-1.06) $I^{2}=83 \%$.

GWG above guidelines was associated with a higher risk for caesarean: USA/Europe (OR 1.26; 1.21-1.33) $I^{2}=0 \%$ and Asia (OR 1.37; 1.30-1.45) $I^{2}=59 \%$. In Asia, the risk was greatest in underweight women (OR 1.51; 1.30-1.45).

Gestational diabetes: Six studies Six studies assessed GDM, but did not use consistent definitions, and had different findings for GWG above guidelines and GDM risk, preventing the intended meta-analysis of GDM and its relationship to GWG.

We were unable to demonstrate statistical significance for comparison of ORs for SGA, preterm birth, LGA, macrosomia and caesarean section between the USA/ Europe and Asian studies due to similar ORs and overlap in CIs.

\section{Subgroup analysis: Asian studies}

Of the eight studies from Asia, four were from China $[16,26,31,36]$, two from Korea [12, 34], with one each from Japan [19] and Taiwan [21].

Results are stratified by country in Additional files 5 and 6 (Table S2: BMI at onset of pregnancy and Table S3: GWG during pregnancy).

\section{Comparison between studies using ethnic-specific regional $\mathrm{BMI}$ categories and WHO BMI categories}

A further analysis comparing studies using regional BMI categories (Chinese and Korean studies) and WHO BMI categories (Japanese and Taiwanese studies) was performed to assess for differences in adherence to 2009 IOM GWG guidelines and differences in maternal and infant adverse outcomes.

Asian studies using ethnic-specific regional BMI categories showed $16 \%$ of women with GWG below guidelines, 33\% within and 51\% above, whereas studies using WHO BMI categories had 60\% with GWG below, 31\% within and $9 \%$ above (Table 5 ).

An additional meta-analysis was performed in Asian studies, where studies using regional BMI categories (Chinese and Korean studies) were compared to those studies using WHO BMI categories (Japanese and Taiwanese studies) (Table 6). Pooled ORs for individual analyses for outcomes are presented in Additional file 7.

SGA, LGA, macrosomia and caesarean section could be examined in a meta-analysis (Table 6).

Wen et al. only included normal weight women, and Yang et al. had women in all weight categories except obese. Yang defined underweight as $<18 \mathrm{~kg} / \mathrm{m}^{2}$.

For OR calculation, Hung, Xiong and Yang combined overweight and obese into one group. The OR was used for the overweight group here. Although Enomoto created separate ORs for overweight and obese, only overweight was used in the meta-analysis as there were no comparison groups for obese. 
a
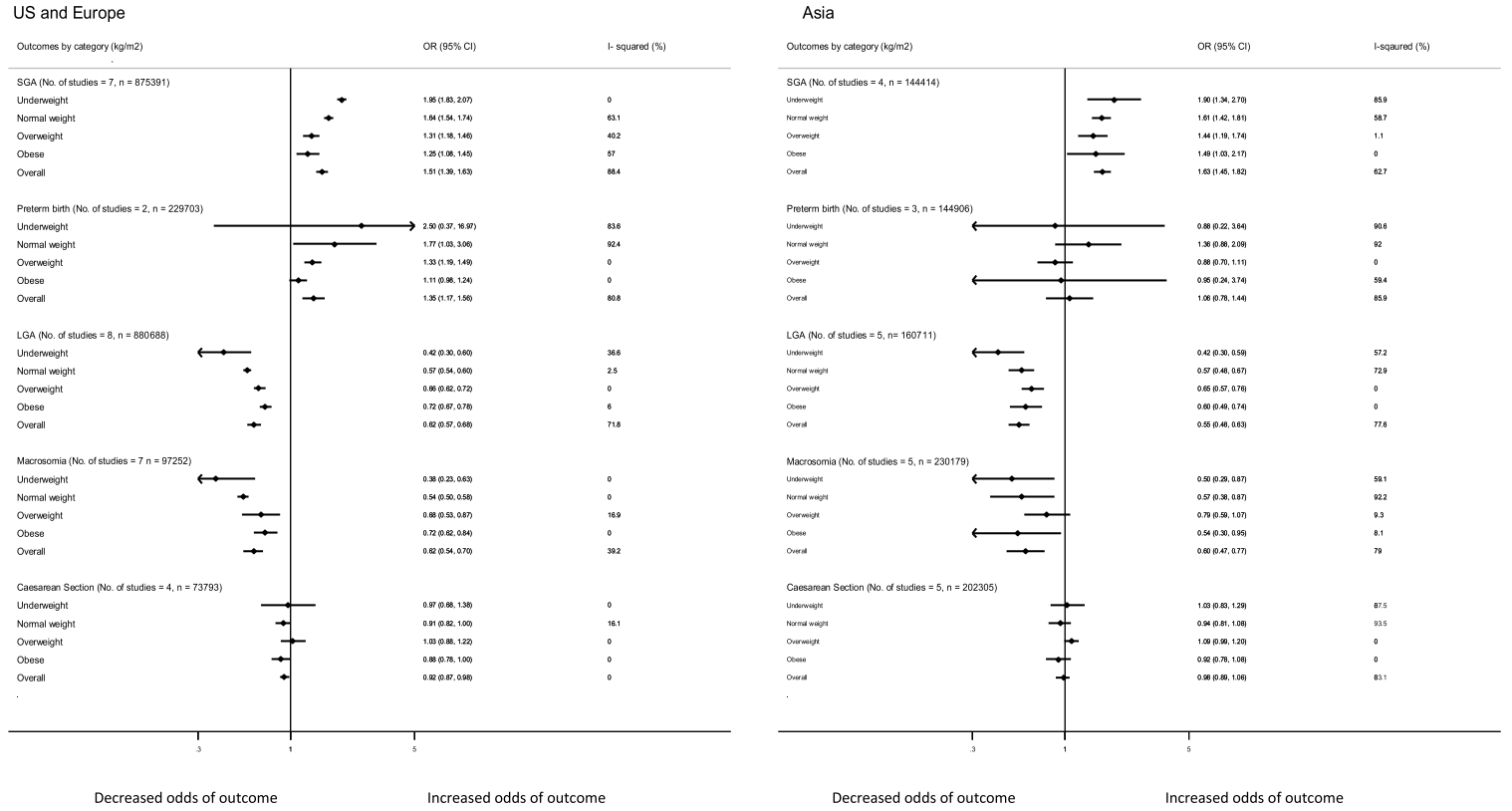

Reference group = women with recommended weight gain in each BMI group

b
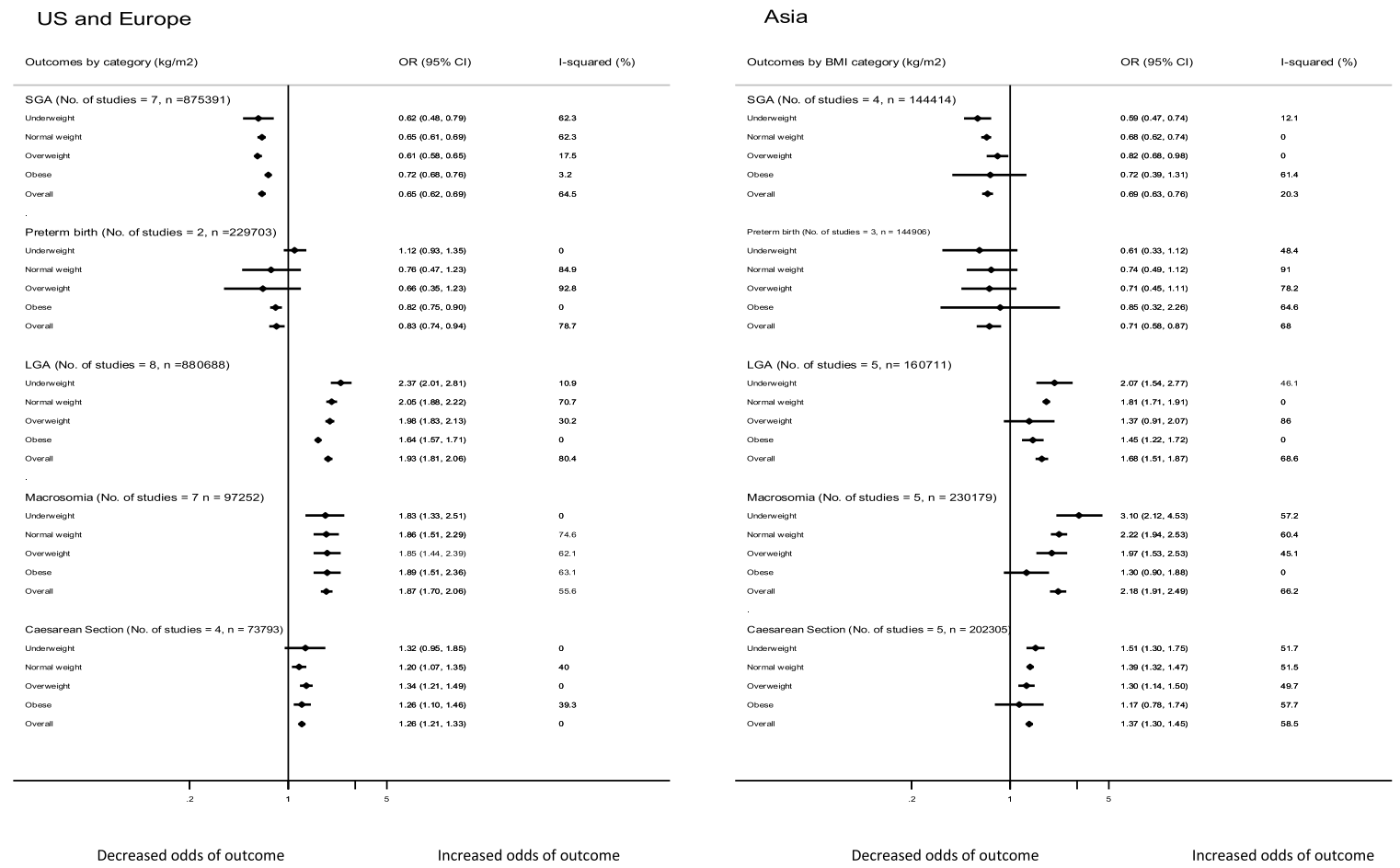

Reference group = women with recommended weight gain in each BMI group

Fig. 2 a Pooled odds ratio for individual outcomes for USA and Europe combined vs Asia, for the association between GWG below guidelines with adverse outcomes. b Pooled odds ratio for individual outcomes for USA and Europe combined vs Asia, for the association between GWG above guidelines with adverse outcomes 
Table 6 Odds ratios for pregnancy outcomes by regions

\begin{tabular}{|c|c|c|c|c|c|c|c|c|}
\hline \multirow[t]{2}{*}{ Outcome } & \multicolumn{2}{|c|}{ USA and Europe } & \multicolumn{2}{|l|}{ Asia overall } & \multicolumn{2}{|c|}{$\begin{array}{l}\text { Regional BMI studies } \\
\text { (Chinese and Korean) }\end{array}$} & \multicolumn{2}{|c|}{$\begin{array}{l}\text { WHO BMI studies } \\
\text { (Japanese and Taiwanese) }\end{array}$} \\
\hline & $\begin{array}{l}\text { GWG } \\
<\text { guidelines }\end{array}$ & $\begin{array}{l}\text { GWG } \\
>\text { guidelines }\end{array}$ & $\begin{array}{l}\text { GWG } \\
<\text { guidelines }\end{array}$ & $\begin{array}{l}\text { GWG } \\
>\text { guidelines }\end{array}$ & $\begin{array}{l}\text { GWG } \\
<\text { guidelines }\end{array}$ & $\begin{array}{l}\text { GWG } \\
>\text { guidelines }\end{array}$ & $\begin{array}{l}\text { GWG } \\
<\text { guidelines }\end{array}$ & $\begin{array}{l}\text { GWG } \\
>\text { guidelines }\end{array}$ \\
\hline$\overline{S G A}$ & $\begin{array}{l}1.51 \\
(1.39,1.63)\end{array}$ & $\begin{array}{l}0.65 \\
(0.62,0.69)\end{array}$ & $\begin{array}{l}1.63 \\
(1.45,1.82)\end{array}$ & $\begin{array}{l}0.69 \\
(0.63,0.76)\end{array}$ & $\begin{array}{l}1.43 \\
(1.2,1.7)\end{array}$ & $\begin{array}{l}0.65 \\
(0.57,0.75)\end{array}$ & $\begin{array}{l}1.77 \\
(1.56,2.01)\end{array}$ & $\begin{array}{l}0.70 \\
(0.63,0.79)\end{array}$ \\
\hline Preterm birth & $\begin{array}{l}1.35 \\
(1.17,1.56)\end{array}$ & $\begin{array}{l}0.83 \\
(0.74,0.94)\end{array}$ & $\begin{array}{l}1.06 \\
(0.78,1.44)\end{array}$ & $\begin{array}{l}0.71 \\
(0.58,0.87)\end{array}$ & N/A & N/A & N/A & $\mathrm{N} / \mathrm{A}$ \\
\hline LGA & $\begin{array}{l}0.62 \\
(0.57,0.68)\end{array}$ & $\begin{array}{l}1.93 \\
(1.81,2.06)\end{array}$ & $\begin{array}{l}0.55 \\
(0.48,0.63)\end{array}$ & $\begin{array}{l}1.68 \\
(1.51,1.87)\end{array}$ & $\begin{array}{l}0.61 \\
(0.48,0.76)\end{array}$ & $\begin{array}{l}1.86 \\
(1.66,2.09)\end{array}$ & $\begin{array}{l}0.49 \\
(0.39,0.62)\end{array}$ & $\begin{array}{l}1.49 \\
(1.18,1.87)\end{array}$ \\
\hline Macrosomia & $\begin{array}{l}0.62 \\
(0.54,0.70)\end{array}$ & $\begin{array}{l}1.87 \\
(1.70,2.06)\end{array}$ & $\begin{array}{l}0.60 \\
(0.47,0.77)\end{array}$ & $\begin{array}{l}2.18 \\
(1.91,2.49)\end{array}$ & $\begin{array}{l}0.75 \\
(0.68,0.83)\end{array}$ & $\begin{array}{l}2.0 \\
(1.71,2.34)\end{array}$ & $\begin{array}{l}0.52 \\
(0.31,0.88)\end{array}$ & $\begin{array}{l}2.76 \\
(2.25,3.38)\end{array}$ \\
\hline Caesarean section & $\begin{array}{l}0.92 \\
(0.87,0.98)\end{array}$ & $\begin{array}{l}1.26 \\
(1.21,1.33)\end{array}$ & $\begin{array}{l}0.98 \\
(0.89,1.06)\end{array}$ & $\begin{array}{l}1.37 \\
(1.30,1.45)\end{array}$ & $\begin{array}{l}0.94 \\
(0.85,1.04)\end{array}$ & $\begin{array}{l}1.43 \\
(1.34,1.52)\end{array}$ & $\begin{array}{l}1.02 \\
(0.92,1.14)\end{array}$ & $\begin{array}{l}1.32 \\
(1.19,1.46)\end{array}$ \\
\hline
\end{tabular}

N/A Unable to perform meta-analysis for preterm birth because less than 2 studies within each region

\section{Meta-regression}

Substantial heterogeneity $\left(I^{2}>50 \%\right)$ was present for GWG below guidelines for SGA (USA/Europe and Asia), preterm birth (USA/Europe and Asia), LGA (USA/Europe and Asia), macrosomia (Asia) and caesarean section (Asia), and for GWG above guidelines for SGA (USA/ Europe), preterm birth (USA/Europe and Asia), LGA (USA/Europe and Asia), macrosomia (USA/Europe and Asia) and caesarean section (Asia).

Where there was sufficient data available, we performed a meta-regression analysis to investigate possible sources of heterogeneity, including percentage of smokers in pregnancy, mean age and percentage nulliparity (Additional file 8) in studies from the USA/Europe and Asia.

The effect of GWG below guidelines on SGA $(p<$ $0.0001)$ for USA/Europe was associated with mean maternal age $(p<0.0005)$ and nulliparity $(p<0.0005)$ and marginally associated with smoking $(p=0.056)$. The GWG below guidelines effect on LGA $(p=0.002)$ for USA/Europe was associated with mean maternal age $(p=0.021)$ and nulliparity $(p<0.005)$. The effect of GWG above guidelines on LGA was significantly associated with nulliparity $(p=0.025)$ and marginally associated with mean age $(p=0.084)$ for the USA/ Europe. Heterogeneity was unexplained for the remaining outcomes.

\section{Publication bias}

There was no evidence of publication bias for SGA, LGA, macrosomia or caesarean section (Additional file 9). Assessment for publication bias was not assessed for preterm birth (less than five studies).

\section{Risk of bias}

Participants were selected from maternity clinics or from large datasets (Additional file 10). Apart from two studies $[17,31]$, there was adequate description of inclusion and exclusion criteria. Studies were mostly retrospective, with three prospective studies [14, 25, 28] and one unspecified [31]. Given the nature of observational studies, attrition bias was not considered relevant. Performance bias was difficult to assess. Very few studies provided information regarding diet/exercise advice given and whether this differed between groups. The overweight and obese women may have been treated more intensively, and this could be a source of bias. However, we postulate this difference would be similar across studies and therefore propose that studies carry a low risk of performance bias overall.

There were three studies with moderate risk of bias and 16 studies with low risk of bias. Main reasons for moderate risk of bias included self-reported final weight (detection bias), self-reported outcome measures (detection bias), failure to report all outcomes (report bias) and insufficient adjustment for confounding variables (confounding bias). Authors on 15 studies reported no conflict of interest.

\section{Discussion}

In this study of 1,309,136 pregnancies, we present a systematic review, meta-analysis and meta-regression incorporating women from diverse ethnicities across three continents, contemporary cohorts and from across the BMI range. We explore ethnic differences in prepregnancy BMI, prevalence of GWG outside IOM guidelines and maternal and neonatal health outcomes between women living in the USA, western Europe and east Asia. Within Asia, we compare studies applying regional and WHO BMI categories. Women in the USA and Europe have higher prepregnancy BMI, higher prevalence of GWG above guidelines and lower rates of GWG below guidelines than women in Asia. However, when applying regional BMI categories, women in Asia have similar 
GWG above guidelines to the other continents, but retain lower prevalence of GWG below guidelines. GWG outside guidelines is associated with adverse health outcomes across all regions. A greater percentage of women in Asia had GWG below guidelines, using WHO BMI (60\%) compared to regional BMI categories (16\%), yet WHO BMI was not accompanied by increased risks of adverse outcomes.

Given that Asian women have greater risks of health complications at a lower BMI, Asian countries often use lower BMI cut-offs for overweight and obese categories. However in 2004, a WHO review of relevant evidence concluded there was no clear cut-off for overweight and obesity for those of Asian ethnicity, and thus WHO did not change their current BMI guidelines [37]. They did, however, identify trigger points of $>23 \mathrm{~kg} / \mathrm{m}^{2}$ and $>27.5 \mathrm{~kg} / \mathrm{m}^{2}$, representing increased and high risks respectively for public health action. In practice, BMI categories commonly used in China $[16,26,31]$ are underweight $B M I<18.5 \mathrm{~kg} / \mathrm{m}^{2}$, normal weight $18.5-23.9 \mathrm{~kg} / \mathrm{m}^{2}$, overweight $24-28 \mathrm{~kg} / \mathrm{m}^{2}$ and obese $\geq 28 \mathrm{~kg} / \mathrm{m}^{2}$. In Korea, the classifications are underweight BMI $<18.5 \mathrm{~kg} / \mathrm{m}^{2}$, normal weight $18.5-22.9 \mathrm{~kg} / \mathrm{m}^{2}$, overweight $23-25 \mathrm{~kg} / \mathrm{m}^{2}$ and obese $\geq 25 \mathrm{~kg} / \mathrm{m}^{2}$ [12, 34]. Studies from Taiwan $[38,39]$ and Japan used WHO BMI categories [40] despite Japanese Society of Obesity guidelines that define obesity at a $\mathrm{BMI} \geq 25 \mathrm{~kg} / \mathrm{m}^{2}$ [41]. The European Board and College of Obstetrics and Gynaecology (EBCOG) [42] notes difficulties in accurately comparing prevalence of prepregnancy BMI groups internationally with heterogeneity of data sets. However, comparison is important across regions to inform our understanding of relationships between GWG and pregnancy outcomes. To the best of our knowledge, this is the only systematic review comparing prepregnancy BMI and exploring relationships to GWG and health outcomes across international settings. We have compared Asian studies using regional and WHO BMI categories in assessment of prepregnancy BMI, GWG and pregnancy health outcomes to explore applicability of regional and WHO BMI categories in applying IOM GWG guidelines.

Applying WHO prepregnancy BMI categories, the USA had the greatest prevalence of overweight and obesity at $43 \%$, consistent with trends from the 20132014 National Health and Nutrition Examination Survey (NHANES), with $37 \%$ of reproductive-aged women obese [43]. This is significant as, preconception, a higher BMI independently increases pregnancy complications including GDM, preeclampsia, caesarean section and LGA $[44,45]$. In contrast, Asia had the greatest prevalence of women in normal weight and underweight categories. A lower BMI preconception is associated with increased risks including SGA [46]. The high prevalence of prepregnancy BMI outside of the healthful range shown here highlights the critical need to focus on achieving healthy preconception weight, especially in the USA, but also across Europe and Asia.

Women in the USA and Europe had higher GWG above guidelines than women in Asia. However, in studies applying ethnic-specific regional BMI categories, women in Asia had similar rates of GWG above guidelines. The prevalence of GWG above guidelines is consistent with observational studies [47-50]. Excess GWG increases adverse pregnancy outcomes, independent of BMI, as demonstrated here, and also increases postpartum weight retention and obesity $[45,51]$. A systematic review of postpartum weight retention in Asian women found that whilst prepregnancy BMI had an impact, GWG was the most important predictor [11], supporting the clinical relevance of our findings on long-term contribution to obesity. Here we have advanced the literature to highlight the high prevalence of GWG above guidelines across the USA, Europe and Asia and show the impact of using regional BMI categories on the application of IOM guidelines.

Exploring health outcomes by GWG, we combined USA and Europe to ensure adequate numbers for meta-analysis and compared USA/Europe to Asia. Across regions, GWG below guidelines was associated with a higher risk of SGA and preterm birth, compared to GWG within guidelines. Likewise across regions, GWG above guidelines was associated with a greater risk for LGA, macrosomia and caesarean section. For women in Asia, adverse outcomes were noted applying both regional and WHO BMI categories. We were generally unable to compare differences in adverse health outcomes because ORs between regions were similar with overlapping CIs. Further research using both regional and WHO BMI categories in all studies of GWG and health outcomes may be useful. We also support the recommendations for standardisation of GWG categories and core outcome parameters to enable more accurate comparisons for future studies [42, 52].

With high prepregnancy BMI, high rates of GWG above guidelines and clear adverse health outcomes shown here across the USA, Europe and Asia, and in our pooled data analysis [5], intervention is clearly vital. The Journal of the American Medical Association editorial accompanying our recent data analysis on GWG discussed barriers to healthful lifestyle intervention during pregnancy in addressing GWG and improving health outcomes [53]. Barriers included inadequate evidence of improvement of adverse pregnancy outcomes and modest changes in GWG. Yet, the largest individual patient data (IPD) analysis of 36 randomised controlled trials in pregnancy $(\sim 12,000$ women) [6], recently published in The $B M J$, demonstrates that even modest reduction in 
excessive GWG improves outcomes, reducing caesarean section, preterm birth and GDM, the latter being particularly modifiable with physical activity intervention. Reported results were independent of maternal characteristics including age, BMI, parity and ethnicity, enhancing generalisability of the findings. It appears that even modest changes to lifestyle and GWG effectively reduce adverse health outcomes, affirming the need for implementation of healthful lifestyle in routine antenatal care for public health impact [54].

There may also be differences to consider within Asia. Comparing Asian studies, prepregnancy BMI was similar. Overall, $16 \%$ of Chinese women were underweight, $74 \%$ normal weight and $9 \%$ overweight and obese. These values are lower than those of recent cohort studies, where $15-28 \%$ of reproductive-aged women in China are above healthy weight $[13,47]$. This contrasted with Japan, with $18 \%, 71 \%$ and $11 \%$ respectively. In China $53 \%$ of women gained above GWG guidelines consistent with the USA and Europe. In Japan GWG below guidelines was $64 \%$, with only $7 \%$ above. These differences arguably occur because WHO BMI categories were applied in Japan. Differences may also relate to ethnic variation. In Singapore, difference in GWG between ethnicities was postulated to be due to difference in diet quality and psychosocial factors [55]. However we postulate that the degree of observed difference primarily related to application of BMI categories. Asian studies have already suggested the need for specific guidelines [56]. In 2000, Chinese-specific guidelines for GWG [57] were developed, but have not been commonly adopted, with most Asian studies using mainly Caucasian-derived IOM GWG guidelines [55]. A call has been made for multi-centre collaboration to create optimal GWG guidelines for Asian women using modified BMI categories [58]. Here however, we demonstrate that applying regional BMI categories generated GWG patterns and health outcomes similar to those in the USA/Europe. With regional BMI categories, apparent higher risks of macrosomia and caesarean section were demonstrated. Overall our data are reassuring for clinicians and policy makers that IOM GWG guidelines are applicable in women of Asian background, provided regional BMI categories are used, to avoid overestimation of GWG below recommendations that are not accompanied by increased risks of adverse outcomes.

Limitations of our study include the lack of cohorts from developing countries and the exclusion of non-English language articles. It did not include studies from eastern Europe and south Asian countries, which have historical and ethnic differences from adjacent western European and east Asian countries respectively, yet this is the broadest systematic review and meta-analysis performed to date. For the meta-analysis, we combined the USA and Europe into one group, due to inadequate reported outcomes. Within each study there may be heterogeneity regarding race/ethnicity, and results should not be interpreted that the sample represented the country of origin. The European and Asian studies did not provide demographic data, and we have assumed the populations in these studies to be largely homogeneous. Studies from the USA do include some women from Asia, and where reported proportions are small, reporting is inconsistent, limiting capacity to interpret the overall prevalence of Asian women in US and European studies. Preterm birth was not adjusted for gestational age, potentially resulting in less total gestational weight gain than would have been otherwise attained. Meta-analyses for GDM could not be performed due to deficiencies in the primary data sets. Heterogeneity among studies may affect the reliability of the results, although this was only relevant for the effect of GWG below guidelines in SGA and LGA in USA/Europe. Lastly, we included studies published before 2009 IOM guidelines, so treating physicians and midwives may have had different GWG targets and guidelines compared to studies from after that time.

Strengths are the inclusion of common maternal and infant risks associated with GWG below and above the IOM 2009 guidelines across the entire prepregnancy BMI spectrum, with an analysis across three continents. Notably, a quarter of the women in these studies were from Asia. This is the only systematic review that has compared Asian studies applying regional compared to WHO BMI categories. We searched four databases, performed a thorough risk of bias appraisal and sought international collaboration to facilitate reanalysis, enabling broad inclusion of data in excess of 1.3 million pregnant women. The collaboration with authors has enabled data in a more homogeneous format for meta-analysis, with unprecedented data integration and meta-analysis.

\section{Conclusions}

In this study of 1,309,136 pregnancies, incorporating women from diverse ethnicities, contemporary cohorts and from across the BMI range, we show that women from the USA and Europe have higher prepregnancy BMI than those from Asia (even when applying regional BMI categories). In the USA and Europe, GWG above guidelines appeared higher than in Asia and GWG below guidelines was highest in Asia. However in Asian studies applying regional BMI categories, GWG above guidelines was similar across the USA, Europe and Asia. In Asia, regional BMI categories may be more applicable than WHO BMI categories when applying IOM GWG guidelines. Across all prepregnancy BMI categories and in different ethnicities, insufficient GWG is associated with increased risk of SGA and preterm birth and excess GWG with increased risk of LGA, macrosomia and 
caesarean section. Risks associated with excess GWG may be higher in women from Asia. These findings have practice and policy implications. This work attests to the broad applicability of the 2009 IOM guidelines, when Asian regional BMI categories are applied. As lifestyle interventions in pregnancy increase attainment of recommended GWG and show health benefits, IOM implementation of GWG guidelines and pregnancy lifestyle interventions should be considered broadly across maternity care $[59,60]$.

\section{Additional files}

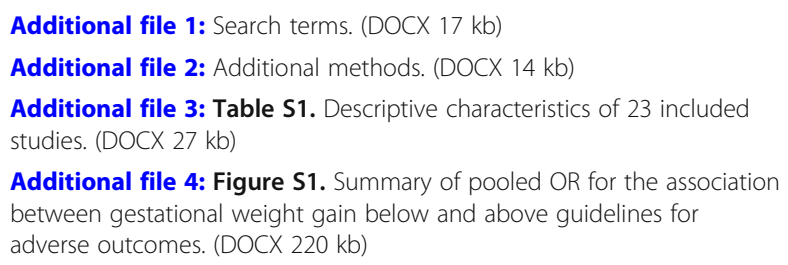

Additional file 4: Figure S1. Summary of pooled OR for the association between gestational weight gain below and above guidelines for adverse outcomes. (DOCX $220 \mathrm{~kb}$ )

Additional file 5: Table S2. Body mass index at onset of pregnancy for Asian studies. (DOCX $17 \mathrm{~kb}$ )

Additional file 6: Table S3. Gestational weight gain during pregnancy for Asian studies. (DOCX $14 \mathrm{~kb}$ )

Additional file 7: Figure S2. Asian subgroup analysis: studies using local BMI categories (China, Korea) vs WHO BMl categories (Japan, Taiwan). Summary of pooled OR for the association between gestational weight gain below and above guidelines for adverse outcomes. (DOCX $106 \mathrm{~kb}$ )

Additional file 8: Table S4. Meta-regression. (DOCX $21 \mathrm{~kb}$ )

Additional file 9: Figure S3. Publication bias. (DOCX $53 \mathrm{~kb}$ )

Additional file 10: Table S5. Summary of risk of bias assessment. (DOCX $20 \mathrm{~kb}$ )

\section{Abbreviations}

BMI: Body mass index; GDM: Gestational diabetes mellitus; GWG: Gestational weight gain; IOM: Institute of Medicine; LGA: Large for gestational age; SGA: Small for gestational age; WHO: World Health Organization

\section{Acknowledgements}

We would like to thank L Rode (Copenhagen University Hospital, Righospitalet, Denmark), T Moore Simas (University of Massachusetts Medical School, Massachusetts, USA), S Park (Centers for Chronic Disease Prevention and Health Promotion (NCCDPHP), Centers for Disease Control and Prevention and M Kominiarek (University of Illinois, Chicago) for their assistance in providing additional data.

\section{Funding}

RFG is supported by an RTS scholarship and SKA by a National Health and Medical Research Council (NHMRC) scholarship. JB and HJT are NHMRC council fellows. The funders had no role in the study design or preparation of the manuscript.

\section{Availability of data and materials}

The datasets used and/or analysed during the current study are available from the corresponding author on reasonable request.

\section{Authors' contributions}

RFG, SKA, MM, SR, JB and HJT participated in the conception, design and implementation of the study. RFG and SKA extracted data. RFG and HJT wrote the first manuscript. RFG and SR performed the statistical analysis. $M H B, N L, G H, F C, H H, Y J K, M H, W S, M H K, A B, R D$ and JHC provided data reanalysis. All authors reviewed and approved the final manuscript.

\section{Ethics approval and consent to participate}

This systematic review and meta-analysis includes previously published observational studies. We could not influence the design of the prior studies upon which this work is based and cannot comment on individual ethics approval or consent. Patients were not involved in the conduct of our epidemiological study, and there is no identifiable data.

\section{Competing interests}

Author/Professor Boyle reports personal fees from Pfizer, outside the submitted work. The authors declare that they have no competing interests.

\section{Publisher's Note}

Springer Nature remains neutral with regard to jurisdictional claims in published maps and institutional affiliations.

\section{Author details}

${ }^{1}$ Monash Centre for Health Research and Implementation, Monash University, Clayton, VIC, Australia. ${ }^{2}$ Monash Diabetes and Endocrine Units, Monash Health, Locked Bag 29, Clayton Rd, Clayton, VIC 3168, Australia. ${ }^{3}$ Kaiser Permanente, Southern California, Los Angeles, USA. 'Tianjin Women's and Children's Health Center, Tianjin, China. ${ }^{5}$ Pennington Biomedical Research Center, Baton Rouge, LA, USA. 'University Hospital, Messina, Italy.

${ }^{7}$ Copenhagen University Hospital, Righospitalet, Copenhagen, Denmark. ${ }^{8}$ Department of Obstetrics and Gynecology, School of Medicine, Ewha Womans University, Seoul, Republic of Korea. ${ }^{9}$ Norwegian Institute of Public Health, Oslo, Norway. ${ }^{10}$ Michigan State University, East Lansing, MI, USA.

${ }^{11}$ Cheil Genetal Hospital and Women's Healthcare Centre Dankook University College of Medicine, Seoul, South Korea. ${ }^{12}$ Department of Development and Regeneration KU Leuven, University of Leuven, Leuven, Belgium. ${ }^{13}$ Faculty of Medicine and Health Sciences, Centre for Research and Innovation in Care (CRIC), University of Antwerp, Antwerp, Belgium. ${ }^{14}$ Faculty of Health and Social Work, Research unit Healthy Living, UC Leuven-Limburg, Leuven, Belgium. ${ }^{15}$ Department of Obstetrics and Gynaecology, University Hospitals KU Leuven, Leuven, Belgium. ${ }^{16}$ Department of Obstetrics, Gynaecology and Fertility, GZA Campus Sint-Augustinus, Wilrijk, Belgium. ${ }^{17}$ University of California, Irvine, CA, USA.

Received: 27 February 2018 Accepted: 13 July 2018

Published online: 31 August 2018

\section{References}

1. Walker LO, Hoke MM, Brown A. Risk factors for excessive or inadequate gestational weight gain among Hispanic women in a U.S.-Mexico border state. J Obstet Gynecol Neonatal Nurs. 2009;38(4):418-29.

2. Weisman CS, Hillemeier MM, Downs DS, Chuang CH, Dyer AM. Preconception predictors of weight gain during pregnancy: prospective findings from the Central Pennsylvania Women's Health Study. Women's Health Issues. 2010;20(2):126-32.

3. Viswanathan M, Siega-Riz AM, Moos MK, Deierlein A, Mumford S, Knaack J, et al. Outcomes of maternal weight gain. Evid Rep Technol Assess. 2008;168:1-223.

4. Rasmussen K, Yaktine AL, editors. Institute of Medicine and National Research Council Committee to reexamine IOM pregnancy weight guidelines. Weight gain during pregnancy: reexamining the guidelines. Washington DC: National Academic Press; 2009.

5. Goldstein RF, Abell SK, Ranasinha S, Misso M, Boyle JA, Black MH, et al. Association of gestational weight gain with maternal and infant outcomes: a systematic review and meta-analysis. JAMA. 2017;317(21):2207-25.

6. International Weight Management in Pregnancy Collaborative Group. Effect of diet and physical activity based interventions in pregnancy on gestational weight gain and pregnancy outcomes: meta-analysis of individual participant data from randomised trials. BMJ. 2017;358:33119.

7. Li G, Chen X, Jang Y, Wang J, Xing X, Yang W, et al. Obesity, coronary heart disease risk factors and diabetes in Chinese: an approach to the criteria of obesity in the Chinese population. Obes Rev. 2002;3(3):167-72.

8. Unnikrishnan R, Pradeepa R, Joshi SR, Mohan V. Type 2 diabetes: demystifying the global epidemic. Diabetes. 2017;66(6):1432-42.

9. Deurenberg P, Deurenberg-Yap M, Guricci S. Asians are different from Caucasians and from each other in their body mass index/body fat per cent relationship. Obes Rev. 2002;3(3):141-6. 
10. Cheng HR, Walker LO, Brown A, Lee JY. Gestational weight gain and perinatal outcomes of subgroups of Asian-American women, Texas, 2009. Women's Hhealth Issues. 2015;25(3):303-11.

11. Cheng HR, Walker LO, Tseng YF, Lin PC. Post-partum weight retention in women in Asia: a systematic review. Obes Rev. 2011;12(10):770-80.

12. Park JH, Lee BE, Park HS, Ha EH, Lee SW, Kim YJ. Association between prepregnancy body mass index and socioeconomic status and impact on pregnancy outcomes in Korea. J Obstet Gynaecol Res. 2011;37(2):138-45.

13. Wang Y, Mi J, Shan XY, Wang QJ, Ge KY. Is China facing an obesity epidemic and the consequences? The trends in obesity and chronic disease in China. Int J Obes. 2007;31(1):177-88.

14. Badon SE, Dyer AR, Josefson JL, Group HSCR. Gestational weight gain and neonatal adiposity in the Hyperglycemia and Adverse Pregnancy Outcome study-North American region. Obesity (Silver Spring). 2014; 22(7):1731-8.

15. Blomberg M. Maternal and neonatal outcomes among obese women with weight gain below the new Institute of Medicine recommendations. Obstet Gynecol. 2011;117(5):1065-70.

16. Wen $T, L V Y$. Inadequate gestational weight gain and adverse pregnancy outcomes among normal weight women in China. Int J Clin Exp Med. 2015; 8(2):2881-6.

17. Chihara I, Hayes DK, Chock LR, Fuddy LJ, Rosenberg DL, Handler AS. Relationship between gestational weight gain and birthweight among clients enrolled in the Special Supplemental Nutrition Program for Women, Infants, and Children (WIC), Hawaii, 2003-2005. Matern Child Health J. 2014; 18(5):1123-31

18. Kominiarek MA, Seligman NS, Dolin C, Gao W, Berghella V, Hoffman M, et al. Gestational weight gain and obesity: is 20 pounds too much? Am J Obstet Gynecol. 2013;209(3):214.e1-11

19. Enomoto K, Aoki S, Toma R, Fujiwara K, Sakamaki K, Hirahara F. Pregnancy outcomes based on pre-pregnancy body mass index in Japanese women. PLoS One. 2016;11(6):e0157081.

20. Durst JK, Sutton AL, Cliver SP, Tita AT, Biggio JR. Impact of gestational weight gain on perinatal outcomes in obese women. Am J Perinatol. 2016; 33(9):849-55.

21. Hung TH, Hsieh TT. Pregestational body mass index, gestational weight gain, and risks for adverse pregnancy outcomes among Taiwanese women: a retrospective cohort study. Taiwan. 2016:55(4):575-81.

22. Higgins JP, Thompson SG, Deeks JJ, Altman DG. Measuring inconsistency in meta-analyses. BMJ. 2003;327(7414):557-60.

23. Black MH, Sacks DA, Xiang AH, Lawrence JM. The relative contribution of prepregnancy overweight and obesity, gestational weight gain, and IADPSG-defined gestational diabetes mellitus to fetal overgrowth. Diabetes Care. 2013:36(1):56-62.

24. Di Benedetto A, D'Anna R, Cannata ML, Giordano D, Interdonato ML, Corrado F. Effects of prepregnancy body mass index and weight gain during pregnancy on perinatal outcome in glucose-tolerant women. Diabetes Metab. 2012;38(1):63-7.

25. Haugen M, Brantsaeter AL, Winkvist A, Lissner L, Alexander J, Oftedal B, et al. Associations of pre-pregnancy body mass index and gestational weight gain with pregnancy outcome and postpartum weight retention: a prospective observational cohort study. BMC Pregnancy Childbirth. 2014;14:201.

26. Li N, Liu E, Guo J, Pan L, Li B, Wang P, et al. Maternal prepregnancy body mass index and gestational weight gain on pregnancy outcomes. PLoS One. 2013;8(12):e82310.

27. Park S, Sappenfield WM, Bish C, Salihu H, Goodman D, Bensyl DM. Assessment of the Institute of Medicine recommendations for weight gain during pregnancy: Florida, 2004-2007. Matern Child Health J. 2011;15(3):289-301.

28. Rode L, Hegaard HK, Kjaergaard H, Moller LF, Tabor A, Ottesen B. Association between maternal weight gain and birth weight. Obstet Gynecol. 2007;109(6):1309-15.

29. Simas TA, Waring ME, Liao X, Garrison A, Sullivan GM, Howard AE, et al. Prepregnancy weight, gestational weight gain, and risk of growth affected neonates. J Women's Health (Larchmt). 2012;21(4):410-7.

30. Vesco KK, Sharma AJ, Dietz PM, Rizzo JH, Callaghan WM, England L, et al. Newborn size among obese women with weight gain outside the 2009 Institute of Medicine recommendation. Obstet Gynecol. 2011 117(4):812-8.

31. Yang S, Peng A, Wei S, Wu J, Zhao J, Zhang Y, et al. Pre-pregnancy body mass index, gestational weight gain, and birth weight: a cohort study in China. PLoS One. 2015;10(6):e0130101.
32. Swank ML, Marshall NE, Caughey AB, Main EK, Gilbert WM, Melsop KA, et al. Pregnancy outcomes in the super obese, stratified by weight gain above and below Institute of Medicine guidelines. Obstet Gynecol. 2014;124(6):1105-10.

33. Shin D, Song WO. Prepregnancy body mass index is an independent risk factor for gestational hypertension, gestational diabetes, preterm labor, and small- and large-for-gestational-age infants. J Matern Fetal Neonatal Med. 2015;28(14):1679-86.

34. Lee JM, Kim MJ, Kim MY, Han JY, Ahn HK, Choi JS, et al. Gestational weight gain is an important risk factor for excessive fetal growth. Obstet. 2014;57(6):442-7.

35. Bogaerts A, Ameye L, Martens E, Devlieger R. Weight loss in obese pregnant women and risk for adverse perinatal outcomes. [Erratum appears in Obstet Gynecol. 2015 Aug;126(2):452]. Obstet Gynecol. 2015;125(3):566-75.

36. Xiong C, Zhou A, Cao Z, Zhang Y, Qiu L, Yao C, et al. Association of prepregnancy body mass index, gestational weight gain with cesarean section in term deliveries of China. Sci. 2016;6:37168.

37. WHO Expert Consultation. Appropriate body-mass index for Asian populations and its implications for policy and intervention strategies. Lancet. 2004;363(9403):157-63.

38. Hung TH, Chen SF, Hsu JJ, Hsieh $\Pi$. Gestational weight gain and risks for adverse perinatal outcomes: a retrospective cohort study based on the 2009 Institute of Medicine guidelines. Taiwan. 2015;54(4):421-5.

39. Tsai YL, Chen LC, Seow KM, Chong KM. The recommendations of the American Institute of Medicine (IOM) for normal and underweight women to reduce the risk of low birth weight. Taiwan. 2015;54(1):1-7.

40. Harita N, Kariya M, Hayashi T, Sato KK, Aoki T, Nakamura K, et al. Gestational bodyweight gain among underweight Japanese women related to smallfor-gestational-age birth. J Obstet Gynaecol Res. 2012;38(9):1137-44.

41. Examination Committee of Criteria for 'Obesity Disease' in Japan. New criteria for 'obesity disease' in Japan. Circ J. 2002;66(11):987-92.

42. Devlieger R, Benhalima K, Damm P, Van Assche A, Mathieu C, Mahmood T, et al. Maternal obesity in Europe: where do we stand and how to move forward?: A scientific paper commissioned by the European Board and College of Obstetrics and Gynaecology (EBCOG). Eur J Obstet Gynecol Reprod Biol. 2016;201:203-8.

43. Flegal KM, Kruszon-Moran D, Carroll MD, Fryar CD, Ogden CL. Trends in obesity among adults in the United States, 2005 to 2014. JAMA. 2016:315(21):2284-91.

44. McIntyre HD, Gibbons KS, Flenady VJ, Callaway LK. Overweight and obesity in Australian mothers: epidemic or endemic? Med J Aust. 2012;196(3):184-8.

45. Nohr EA, Vaeth M, Baker JL, Sorensen T, Olsen J, Rasmussen KM. Combined associations of prepregnancy body mass index and gestational weight gain with the outcome of pregnancy. Am J Clin Nutr. 2008;87(6):1750-9.

46. Zhang B, Yang S, Yang R, Wang J, Liang S, Hu R, et al. Maternal prepregnancy body mass index and small for gestational age births in Chinese women. Paediatr Perinat Epidemiol. 2016;30(6):550-4.

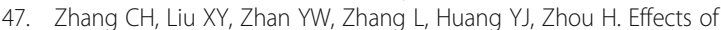
prepregnancy body mass index and gestational weight gain on pregnancy outcomes. Asia Pac J Public Health. 2015;27(6):620-30.

48. Liu L, Hong Z, Zhang L. Associations of prepregnancy body mass index and gestational weight gain with pregnancy outcomes in nulliparous women delivering single live babies. Sci. 2015;5:12863.

49. Huang A, Ji Z, Zhao W, Hu H, Yang Q, Chen D. Rate of gestational weight gain and preterm birth in relation to prepregnancy body mass indices and trimester: a follow-up study in China. Reprod Health. 2016;13(1):93.

50. Hannaford KE, Tuuli MG, Odibo L, Macones GA, Odibo AO. Gestational weight gain: association with adverse pregnancy outcomes. Am J Perinatol. 2017;34(2):147-54

51. Margerison Zilko CE, Rehkopf D, Abrams B. Association of maternal gestational weight gain with short- and long-term maternal and child health outcomes. Am J Obstet Gynecol. 2010;202(6):574.e1-8.

52. Rogozinska E, D'Amico MI, Khan KS, Cecatti JG, Teede H, Yeo S, et al. Development of composite outcomes for individual patient data (IPD) metaanalysis on the effects of diet and lifestyle in pregnancy: a Delphi survey. BJOG. 2016;123(2):190-8.

53. Caughey AB. Gestational weight gain and outcomes for mothers and infants. JAMA. 2017;317(21):2175-6.

54. Harrison CL, Skouteris H, Boyle J, Teede HJ. Preventing obesity across the preconception, pregnancy and postpartum cycle: implementing research into practice. Midwifery. 2017:52:64-70.

55. Koh H, Ee TX, Malhotra R, Allen JC, Tan TC, Ostbye T. Predictors and adverse outcomes of inadequate or excessive gestational weight gain in an Asian population. J Obstet Gynaecol Res. 2013;39(5):905-13. 
56. Ee TX, Allen JC Jr, Malhotra R, Koh H, Ostbye T, Tan TC. Determining optimal gestational weight gain in a multiethnic Asian population. J Obstet Gynaecol Res. 2014;40(4):1002-8.

57. Wong W, Tang NL, Lau TK, Wong TW. A new recommendation for maternal weight gain in Chinese women. J Am Diet Assoc. 2000;100(7):791-6.

58. Choi SK, Park IY, Shin JC. The effects of pre-pregnancy body mass index and gestational weight gain on perinatal outcomes in Korean women: a retrospective cohort study. Reprod Biol Endocrinol. 2011;9:6.

59. Poston L, Caleyachetty R, Cnattingius S, Corvalan C, Uauy R, Herring S, et al. Preconceptional and maternal obesity: epidemiology and health consequences. Lancet Diabetes Endocrinol. 2016;4(12):1025-36.

60. Ma RC, Schmidt MI, Tam WH, Mclntyre HD, Catalano PM. Clinical management of pregnancy in the obese mother: before conception, during pregnancy, and post partum. Lancet Diabetes Endocrinol. 2016;4(12):1037-49.

Ready to submit your research? Choose BMC and benefit from:

- fast, convenient online submission

- thorough peer review by experienced researchers in your field

- rapid publication on acceptance

- support for research data, including large and complex data types

- gold Open Access which fosters wider collaboration and increased citations

- maximum visibility for your research: over $100 \mathrm{M}$ website views per year

At $\mathrm{BMC}$, research is always in progress.

Learn more biomedcentral.com/submissions 